\title{
A questão étnico-racial no ensino de português para falantes de outras línguas (PFOL) nas universidades públicas da Bahia
}

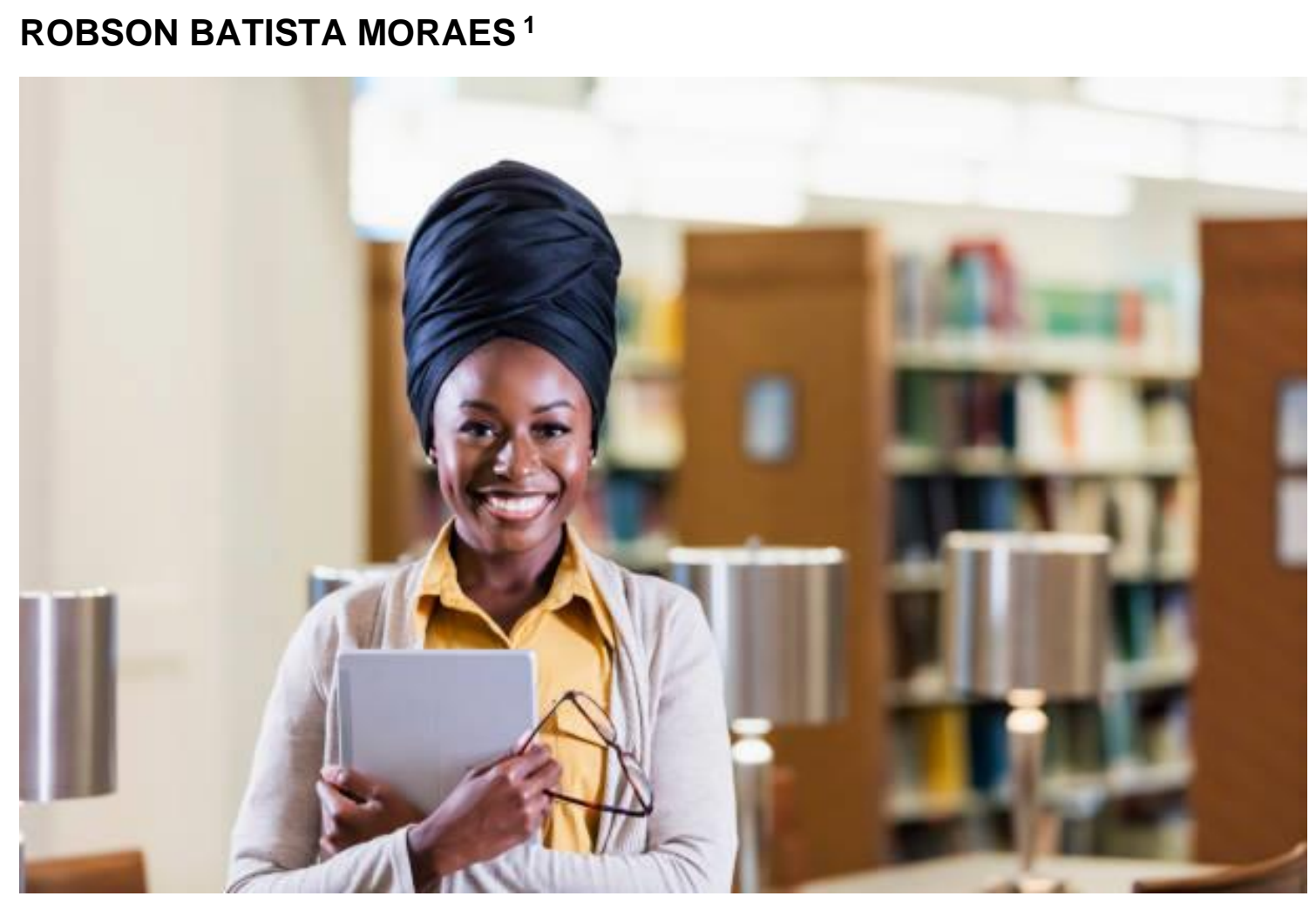

RESUMO: O objetivo deste trabalho de caráter bibliográfico e documental é mapear as ações de produção científica e o ensino/aprendizagem de Português para Falantes de outras Línguas (PFOL) no contexto das universidades públicas da Bahia e problematizar qual é a atenção conferida à questão étnico-racial, sobretudo, nos currículos dos cursos de Letras Vernáculas e nas pesquisas desenvolvidas no âmbito da graduação e pósgraduação, no campo específico de PFOL, em quatro universidades públicas, a saber: Universidade federal da Bahia - UFBA, Universidade Estadual de Feira de Santana UEFS, Universidade Estadual de Santa Cruz -UESC e Universidade da Integração Internacional da Lusofonia Afro-Brasileira. - UNILAB.

PALAVRAS-CHAVES: A questão étnico-racial no ensino de Português para Falantes de Outras Línguas (PFOL), Racismo antinegros, Universidades públicas baianas.

\footnotetext{
${ }^{1}$ Graduado em Letras vernáculas e Graduando em Letras - Português como Língua Estrangeira pela Universidade Federal da Bahia - UFBA. E-mail: robsonbmoraes5@gmail.com
} 


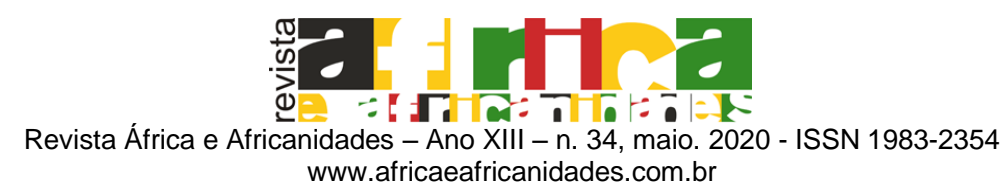

\section{INTRODUÇÃO}

Este artigo, fruto de uma investigação em andamento e de cunho bibliográfico e documental, visa apresentar alguns aspectos sobre mapeamentos de pesquisas científicas desenvolvidas no cenário das universidades públicas do estado da Bahia, nas quais abarcam como temática central a questão étnicoracial, na área específica de ensino e aprendizagem de Português para Falantes de outras Línguas (PFOL) Além disso, visa também apontar a atenção conferida a tal questão na matriz curricular dos cursos de Letras Vernáculas e problematizar suas implicações para a formação de docentes culturalmente sensíveis e engajados na luta antirracista.

De acordo com Moraes e Souza (2017), o ensino de português a falantes de outras línguas tem avançado de forma bastante significativa no estado da Bahia, mas é essencial expor que no cenário atual o grande marco desse processo foi a implantação da graduação de PLE na Universidade Federal da Bahia, no ano de 2006 em Salvador, sendo a primeira instituição do Nordeste e segunda Universidade pública brasileira, após a iniciativa da Universidade de Brasília - UNB, a implantar esse curso no âmbito da graduação, além também da promoção do ensino de PFOL no plano da pesquisa e extensão.

Ainda nessa perspectiva, além da iniciativa de implantação do curso de português para falantes estrangeiros realizado pela UFBA, outras universidades públicas baianas também tomaram a atitude de criar ações de ensino e pesquisa, como: a Universidade Estadual de Santa Cruz - UESC, Universidade Estadual de Feira de Santana -UEFS, a Universidade da Integração Internacional da Lusofonia Afro-Brasileira. - UNILAB entre outras instituições privadas.

É pertinente salientar que na UFBA já existe o tripé: Ensino, Pesquisas e Extensão de PFOL; na UEFS há iniciativas no âmbito da extensão e uma pesquisa desenvolvida na pós-graduação; na UNILAB, as ações ocorrem no âmbito da extensão e existem disciplinas específicas de português para estrangeiros no currículo, além da UESC, na qual existem também dezenas de pesquisas desenvolvidas, e algumas em andamento, ademais de iniciativas na extensão e em disciplinas da matriz curricular de Letras. Cabe sublinhar que todas essas informações foram colhidas dos sítios virtuais das respectivas instituições aqui supracitadas.

Para Aparecido e Neves (2013, p. 134), o ensino de português para estrangeiros oferece muitos desafios aos professores no contexto de ensino e aprendizagem como um todo. Nessa mesma direção, o ensino de português para estrangeiros no contexto das universidades públicas baianas deve assumir o desafio de abordar a diversidade cultural africana e afro-brasileira, sua relevante participação, bem como o papel ativo dos negros e negras no processo de constituição do português brasileiro, conforme expõe Mattos e Silva (2003).

Esta investigação insere-se no campo epistemológico da Linguística Aplicada (LA), que tem como finalidade produzir pesquisas a partir de investigações de natureza aplicada sobre questões de linguagem na prática social. Assim, concentra-se na grande área da linguagem, na subárea de ensino 


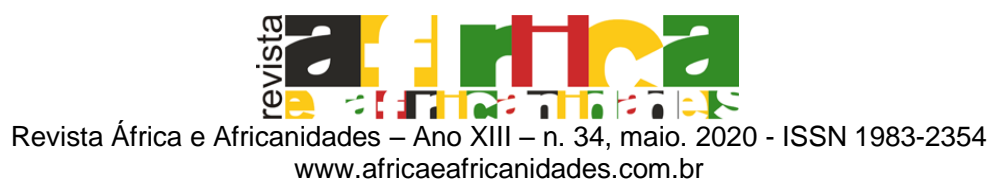

e aprendizagem de línguas, em especial, a do Ensino de Português para Estrangeiros, conforme assegura Almeida Filho (2011).

A Linguística Aplicada possui natureza interdisciplinar e, portanto, tenta sempre dialogar com outros campos do saber, buscando aproximar-se cada vez mais de demandas como: educação e pobreza, questões de gênero, classe e diversas outras de âmbito social e, sobretudo, da questão étnico-racial. Todavia, conforme será em seguida exposto nos dados, as questões raciais ainda são muito incipientes nas temáticas das pesquisas científicas produzidas no campo de PFOL e nos currículos dos cursos de Letras Vernáculas, no contexto das universidades públicas baianas.

\section{MOTIVAÇÃO E ANÁLISE DE DADOS DA PESQUISA}

A principal motivação para a construção deste artigo deu-se durante 0 processo de levantamento de dados da pesquisa científica, que se constituiu de uma sondagem feita em sítios virtuais acerca das investigações científicas realizadas no campo específico do ensino de Português para Falantes de Outras Línguas (PFOL). Tais consultas foram efetuadas nos sites das universidades públicas do estado da Bahia, a saber: Universidade Federal da Bahia - UFBA, Universidade Estadual Santa Cruz - UESC, Universidade Estadual de feira de Santana - UEFS e na Universidade da Integração Internacional da Lusofonia Afro-Brasileira. - UNILAB, entre os anos de 2003 a 2020, no âmbito da graduação e da pós-graduação.

Para além da investigação que se refere às produções científicas desenvolvidas no campo da Linguística Aplicada, em especial, na área de ensino e aprendizagem de Língua Portuguesa para Estrangeiros, outra justificativa a qual considero muito pertinente e que, em certa medida, suscitou-me a escrever este texto, foi a constatação da inexistência de disciplinas obrigatórias concernentes às relações étnico-raciais na matriz curricular dos cursos de Letras Vernáculas da UFBA. Compondo a matriz dos cursos de Letras, há apenas, aproximadamente, (quatro) disciplinas optativas específicas da área de Literatura, as quais possuem como foco questões étnico-raciais, como expõe o quadro 1 a seguir:

Quadro 1. Disciplinas sobre a questão Étnico-Racial no Curso de Letras- UFBA

\begin{tabular}{|c|c|c|c|c|}
\hline $\begin{array}{c}\text { Disciplinas } \\
\text { sobre questões } \\
\text { Étnico-Raciais }\end{array}$ & Natureza & $\begin{array}{c}\text { Semestre } \\
\text { vigente }\end{array}$ & Departamento & Carga horária \\
\hline $\begin{array}{c}\text { Literaturas } \\
\text { Africanas de } \\
\text { Língua } \\
\begin{array}{c}\text { Portuguesa e o } \\
\text { Cânone } \\
\text { Ocidental LET - } \\
\text { C47 }\end{array}\end{array}$ & Optativa & 2015.2 & $\begin{array}{c}\text { Letras } \\
\text { Vernáculas }\end{array}$ & $68 \mathrm{~h}$ \\
\hline $\begin{array}{c}\text { Poesia Africana } \\
\text { em Língua } \\
\text { Portuguesa } \\
\text { LET- C50 }\end{array}$ & Optativa & 2015.2 & $\begin{array}{c}\text { Letras } \\
\text { Vernáculas }\end{array}$ & $68 \mathrm{~h}$ \\
\hline
\end{tabular}




\begin{tabular}{|c|c|c|c|c|}
\hline $\begin{array}{c}\text { Narrativas } \\
\text { Africanas de } \\
\text { Língua } \\
\begin{array}{c}\text { Portuguesa } \\
\text { LET- C53 }\end{array}\end{array}$ & Optativa & 2015.2 & $\begin{array}{c}\text { Letras } \\
\text { vernáculas }\end{array}$ & $68 \mathrm{~h}$ \\
\hline $\begin{array}{c}\text { Crítica Literária } \\
\text { e Culturas } \\
\text { Africana e } \\
\text { Africanista } \\
\text { LET - C55 }\end{array}$ & Optativa & 2015.2 & $\begin{array}{c}\text { Letras } \\
\text { Vernáculas }\end{array}$ & $68 \mathrm{~h}$ \\
\hline
\end{tabular}

Fonte: Matriz curricular do curso de Letras da Universidade Federal da Bahia via SIACWEB.

A ausência de disciplinas obrigatórias sobre a questão étnico-racial na matriz do curso de Letras Vernáculas da Universidade Federal de Bahia, cujo estado no qual está situada possui uma população majoritariamente negra é um fato muito problemático, visto que o professor em formação corre o risco de passar por toda a licenciatura sem necessariamente cursar tais disciplinas e, assim, não ter efetivamente uma formação bem qualificada para tratar dessa demanda no contexto da educação escolar.

Por outro lado, se as referidas disciplinas fossem oferecidas como obrigatórias, todos os estudantes do curso iriam, indistintamente, cursá-las e, em certa medida, teriam orientações básicas para aplicar ao ensino de línguas, além de usufruírem de um suporte teórico-metodológico para desenvolverem pesquisas nesse campo e, assim, obterem insumos suficientes para enfrentarem problemas como discriminação racial e racismo, os quais, infelizmente, ainda persistem no cenário educacional.

Nesse sentido, surpreendentemente, foram constatadas por meio de consultas ao Repositório Institucional da UFBA, no sítio virtual do Programa de Pós-Graduação em Língua e Cultura - PPGLINC, UEFS e UESC, a produção de pouquíssimas pesquisas científicas que abarcam no centro de suas temáticas questões relacionadas à História e Cultura Africana e Afro-brasileira no ensino e aprendizagem de Português para Falantes de outras Línguas. Reitera-se que foram constatadas apenas duas pesquisas com a temática sobre a questão étnico-racial na UFBA, uma concluída e outra em andamento, como se pode visualizar posteriormente no quadro de $\mathrm{n}^{\circ}-3$.

Sendo assim, pode-se inferir que, mesmo tratando-se de pesquisas científicas desenvolvidas no contexto de universalidades públicas na região baiana, as quais estão situadas em um estado cuja população é constituída por mais de $80 \%$ de negros (pretos e pardos), conforme atestam os dados do Instituto Brasileiro de Geografia e Estatística (IBGE), as culturas africanas e afrobrasileiras têm recebido pouca atenção ou não têm sido abordadas de forma significativa nas pesquisas científicas.

Quanto à UNILAB, até o período do processo da coleta de dados, foi verificado no sítio virtual dessa mesma universidade a não constatação de produções científicas com esse viés, assim como na UEFS, na qual havia apenas uma pesquisa desenvolvida nessa área em análise, cuja temática não abarcava questões étnico-raciais, conforme demonstrado no quadro de ํo 2 abaixo: 
Quadro 2 - Pesquisa Científica produzida na área de PFOL na UEFS.

\begin{tabular}{|c|c|c|c|c|}
\hline Pesquisador (a) & $\begin{array}{c}\text { Ano de } \\
\text { Conclusão }\end{array}$ & Tema & Orientador (a) & Instituição/Programa \\
\hline $\begin{array}{c}\text { Érika Ramos de } \\
\text { Lima Aureliano }\end{array}$ & $\begin{array}{c}\text { Dissertação de } \\
\text { Mestrado -2019 }\end{array}$ & $\begin{array}{c}\text { O tratamento da } \\
\text { variação } \\
\text { linguística em } \\
\text { materiais } \\
\text { didáticos de } \\
\text { Português e de } \\
\text { Espanhol como } \\
\text { línguas } \\
\text { adicionais }\end{array}$ & Josane Moreira & PPGEL/UEFS \\
\hline
\end{tabular}

Fonte: Dados elaborados pelo autor a partir de informações colhidas do site do Programa de Pós-Graduação em estudos Linguísticos da Universidade Estadual de feira de Santana - UEFS.

As pesquisas realizadas e supracitadas evidenciam/comprovam através dos dados colhidos e ilustrados respectivamente nos quadros 2 e 3 que, apesar dos discursos proferidos por estudiosos da área de PFOL sobre as pretensões de um ensino de línguas estrangeiras pautado, preferencialmente, em uma perspectiva intercultural, nos quais afirmam a pertinência do diálogo entre/inter culturas, assim como recomendam que o ensino de uma língua-alvo não deve ser realizado dissociado da cultura do seu entorno. Entretanto, até o presente momento, tal perspectiva não tem sido eficazmente colocada em prática. Os dados pesquisados revelam que a diversidade étnico-racial baiana tem sido tratada com pouca prioridade e preterida nas pesquisas. Portanto, qual perspectiva de ensino de língua-cultura é mesmo efetivamente priorizada e abordada no ensino e aprendizagem de PFOL no contexto das universidades públicas localizadas no estado constituído pela população mais negra do país? Fica a questão!

Quadro 3. Pesquisas científicas sobre a questão étnico-racial na UFBA

\begin{tabular}{|c|c|c|c|c|}
\hline \multicolumn{5}{|c|}{ Quadro de pesquisas científicas sobre à questão étnico-racial no ensino de PFOL desenvolvidas na } \\
Universidades Federal da Bahia - UFBA (2003-2020)
\end{tabular}




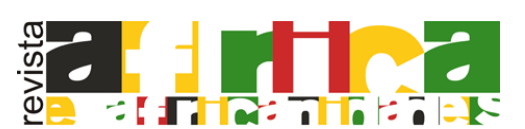

Revista África e Africanidades - Ano XIII - n. 34, maio. 2020 - ISSN 1983-2354

www.africaeafricanidades.com.br

\begin{tabular}{|c|c|c|c|c|}
\hline & & $\begin{array}{c}\text { Português língua } \\
\text { Estrangeira }\end{array}$ & & \\
\hline $\begin{array}{l}\text { Laura Camila } \\
\text { Braz de Almeida }\end{array}$ & $\begin{array}{l}\text { Dissertação de } \\
\text { mestrado-2005 }\end{array}$ & $\begin{array}{c}\text { Avaliação da } \\
\text { compreensão e produção } \\
\text { de textos no ensino- } \\
\text { aprendizagem de, } \\
\text { português como segunda } \\
\text { língua }\end{array}$ & Iracema Luiza & UFBA/PPGLinc \\
\hline $\begin{array}{l}\text { Kaline Araújo } \\
\text { Mendes }\end{array}$ & $\begin{array}{l}\text { Dissertação de } \\
\text { mestrado -2006 }\end{array}$ & $\begin{array}{c}\text { Português Língua } \\
\text { Estrangeira: Uma Análise } \\
\text { do Livro Didático. }\end{array}$ & Iracema Luiza & UFBA/PPGLinc \\
\hline $\begin{array}{l}\text { Laura Camila } \\
\text { Braz de Almeida }\end{array}$ & $\begin{array}{c}\text { Tese de } \\
\text { Doutorado-2009 }\end{array}$ & $\begin{array}{c}\text { A avaliação da produção } \\
\text { escrita em alunos } \\
\text { aprendizes de Português } \\
\text { LE/L2 }\end{array}$ & Iracema Luiza & UFBA/PPGLinc \\
\hline $\begin{array}{c}\text { Luana Moreira } \\
\text { Reis }\end{array}$ & $\begin{array}{l}\text { Dissertação de } \\
\text { Mestrado-2012 }\end{array}$ & $\begin{array}{c}\text { O Ensino do Português } \\
\text { como Língua Estrangeira } \\
\text { (PLE): desafios, } \\
\text { tendências } \\
\text { contemporâneas e } \\
\text { políticas institucionais. }\end{array}$ & Edleise Mendes & UFBA/PPGLinc \\
\hline $\begin{array}{l}\text { Camila Alves } \\
\text { Gusmão }\end{array}$ & $\begin{array}{l}\text { Dissertação de } \\
\text { Mestrado -2013 }\end{array}$ & $\begin{array}{c}\text { As representações } \\
\text { culturais no } \\
\text { ensino/aprendizagem de } \\
\text { Português L2: um diálogo } \\
\text { com a perspectiva } \\
\text { intercultural. }\end{array}$ & Edleise Mendes & UFBA/PPGlinc \\
\hline $\begin{array}{c}\text { Marília Pinheiro } \\
\text { Pereira }\end{array}$ & $\begin{array}{l}\text { Dissertação de } \\
\text { Mestrado-2015 }\end{array}$ & $\begin{array}{l}\text { O ensino de português } \\
\text { como língua de herança } \\
\text { em uma escola bilíngue } \\
\text { na Alemanha. }\end{array}$ & Edleise Mendes & UFBA/PPGlinc \\
\hline $\begin{array}{l}\text { Lucas Rodrigues } \\
\text { Soares da } \\
\text { Conceição }\end{array}$ & $\begin{array}{c}\text { Iniciação } \\
\text { Científica -2015 }\end{array}$ & $\begin{array}{l}\text { Contextos históricos de } \\
\text { atuação de professores de } \\
\text { português como LE/L2: } \\
\text { mapeamentos iniciais. }\end{array}$ & Edleise Mendes & UFBA/CNPQ \\
\hline $\begin{array}{c}\text { Robson Batista } \\
\text { Moraes }\end{array}$ & $\begin{array}{c}\text { Iniciação } \\
\text { Científica-2015 }\end{array}$ & $\begin{array}{l}\text { O português como LE/L2 } \\
\text { na América Latina: } \\
\text { mapeamentos iniciais }\end{array}$ & Edleise Mendes & UFBA \\
\hline $\begin{array}{l}\text { Diogo Oliveira do } \\
\text { Espírito Santo. }\end{array}$ & $\begin{array}{l}\text { Dissertação de } \\
\text { Mestrado-2017 }\end{array}$ & $\begin{array}{c}\text { Crenças e Materiais } \\
\text { Didáticos Interculturais No } \\
\text { Processo de Ensino E } \\
\text { Aprendizagem de uma } \\
\text { Turma de PFOL nos } \\
\text { Estados Unidos }\end{array}$ & Denise Scheyerl & UFBA/PPGLinc \\
\hline $\begin{array}{l}\text { Mauricio José de } \\
\text { Souza Neto }\end{array}$ & Mestrado-2018 & $\begin{array}{c}\text { CELPE-BRAS e DIPLE: a } \\
\text { proficiência em português } \\
\text { como língua estrangeira } \\
\text { em paralaxe. } \\
\end{array}$ & Maria Ortiz & UFBA/PPGLinc \\
\hline $\begin{array}{l}\text { Regina Lúcia } \\
\text { Egito Soares. }\end{array}$ & $\begin{array}{c}\text { Tese de } \\
\text { Doutorado-2019 }\end{array}$ & $\begin{array}{l}\text { E, no entanto, é preciso } \\
\text { cantar! Música popular } \\
\text { como mediadora do } \\
\text { ensino-aprendizagem de } \\
\text { Português Língua } \\
\text { Estrangeira (PLE) }\end{array}$ & Edleise Mendes & UFBA/PPGLinc \\
\hline $\begin{array}{l}\text { Lucas Rodrigues } \\
\text { Soares da } \\
\text { Conceição }\end{array}$ & $\begin{array}{l}\text { Dissertação de } \\
\text { Mestrado-2019 }\end{array}$ & $\begin{array}{c}\text { Uma experiência com a } \\
\text { língua portuguesa no } \\
\text { brasil: representações dos } \\
\text { alunos do profici/ple } \\
\text { (UFBA) }\end{array}$ & Edleise Mendes & UFBA/PPGLinc \\
\hline $\begin{array}{l}\text { Sara Oliveira da } \\
\text { Cruz }\end{array}$ & $\begin{array}{l}\text { Dissertação de } \\
\text { Mestrado -2019 }\end{array}$ & $\begin{array}{l}\text { O Blog nas aulas de } \\
\text { Português como Língua } \\
\text { Estrangeira/Segunda } \\
\text { Língua: uma proposta de }\end{array}$ & Edleise Mendes & UFBA/PPGLinc \\
\hline
\end{tabular}




\begin{tabular}{|c|c|c|c|c|}
\hline & & $\begin{array}{l}\text { ensino em perspectiva } \\
\text { intercultural e crítica }\end{array}$ & & \\
\hline $\begin{array}{l}\text { Heide Matos } \\
\text { Duarte }\end{array}$ & $\begin{array}{l}\text { Dissertação de } \\
\text { Mestrado-2019 }\end{array}$ & $\begin{array}{l}\text { "De que África você vem"? } \\
\text { Uma análise de } \\
\text { estereótipos a partir dos } \\
\text { relatos de experiência de } \\
\text { alunos africanos do PEC- } \\
\text { G da UFBA }\end{array}$ & Lívia Baptista & UFBA/PPGLinc \\
\hline $\begin{array}{l}\text { Ilma Teles } \\
\text { Menezes da Luz }\end{array}$ & $\begin{array}{l}\text { Dissertação de } \\
\text { Mestrado em } \\
\text { andamento- } 2019\end{array}$ & $\begin{array}{l}\text { Cruzando fronteiras e } \\
\text { reconstruindo vidas: } \\
\text { experiências de } \\
\text { refugiados em contexto de } \\
\text { Língua de Acolhimento - } \\
\text { escutas e desafios }\end{array}$ & Gilvan Muller & UFBA/PPGLinc \\
\hline $\begin{array}{l}\text { Robson Batista } \\
\text { Moraes }\end{array}$ & $\begin{array}{c}\text { Dissertação de } \\
\text { Mestrado em } \\
\text { andamento-2019 }\end{array}$ & $\begin{array}{c}\text { A questão étnico-racial no } \\
\text { ensino e a Aprendizagem } \\
\text { de Português para } \\
\text { Falantes de Outras } \\
\text { Línguas (PFOL) nas } \\
\text { Universidades Públicas da } \\
\text { Bahia } \\
\end{array}$ & Iracema Luiza & UFBA/PPGLinc \\
\hline $\begin{array}{c}\text { Marília Pinheiro } \\
\text { Pereira }\end{array}$ & $\begin{array}{c}\text { Tese de } \\
\text { doutorado em } \\
\text { andamento }-2019\end{array}$ & $\begin{array}{l}\text { Práticas e representações } \\
\text { no ensino de línguas } \\
\text { pluricêntricas em } \\
\text { contextos multilíngue e } \\
\text { multicultural: Intervenções } \\
\text { didáticas nas aulas de } \\
\text { português como língua de } \\
\text { herança na Alemanha. }\end{array}$ & Edleise Mendes & UFBA/PPGLinc \\
\hline $\begin{array}{c}\text { Rafaela Santos } \\
\text { de Souza }\end{array}$ & $\begin{array}{c}\text { Dissertação de } \\
\text { Mestrado em } \\
\text { andamento-2019 }\end{array}$ & $\begin{array}{l}\text { Competência performativa } \\
\text { e autoria na produção } \\
\text { escrita de falantes } \\
\text { multilíngues: um estudo } \\
\text { de caso de alunos } \\
\text { africanos do PEC-G }\end{array}$ & Lívia Baptista & UFBA/PPGLinc \\
\hline $\begin{array}{l}\text { Manuela de } \\
\text { Oliveira Inácio }\end{array}$ & $\begin{array}{c}\text { Tese de } \\
\text { Doutorado em } \\
\text { andamento- } 2019\end{array}$ & $\begin{array}{c}\text { Assistentes de PLE/PL2 } \\
\text { na França: um olhar } \\
\text { interpretativo de narrativas } \\
\text { e experiências } \\
\end{array}$ & Lívia Baptista & UFBA/PPGLinc \\
\hline $\begin{array}{l}\text { Gabriela Silva } \\
\text { De-Gino }\end{array}$ & $\begin{array}{c}\text { Dissertação de } \\
\text { Mestrado em } \\
\text { andamento -2020 }\end{array}$ & $\begin{array}{c}\text { Uso das Unidades } \\
\text { Didáticas do Portal do } \\
\text { Professor de Português } \\
\text { como língua } \\
\text { Estrangeira/não-materna } \\
\text { (PPPLE) na prática: } \\
\text { Avaliar para Aperfeiçoar }\end{array}$ & Edleise Mendes & UFBA/PPGLinc \\
\hline
\end{tabular}

Fonte: Dados elaborados pelo autor a partir das informações disponíveis na Plataforma Lattes e site do Programa de Pós-Graduação de Língua e Cultura -PPGLinc da UFBA.

Os dados das pesquisas científicas os quais levantei junto à UFBA, conforme exposto no Quadro de № 3, e da UESC, assim como demonstrado nos dados do Quadro de № 4, reiteram que, em certa medida, ainda não é a cultura de matriz africana nem muito menos a cultura afro-brasileira priorizadas nas pesquisas elaboradas no campo do ensino de PFOL realizadas nos últimos anos nas Instituições Públicas de Ensino Superior da Bahia.

Convém explicitar que, em certa medida, as instituições baianas não têm efetivamente incluído nas suas pesquisas as questões raciais, mesmo após a criação da Lei Federal 10639/2003, de 09 de janeiro de 2003, que alterou a Lei de Diretrizes e Bases da Educação Nacional № 9.394 de 20 de dezembro de 1996, a qual prevê a obrigatoriedade do ensino da História e Cultura afro- 
brasileira e africana (BRASIL, 2010), e também do Plano Nacional de Implementação das Diretrizes Curriculares Nacionais para educação das relações étnico-raciais e para o ensino de História e Cultura afro-brasileira e africana (BRASIL, 2010). Os dados demonstrados reiteram que as pesquisas no campo de PFOL ainda conferem pouca atenção às questões étnico-raciais no cenário das universidades públicas, como é possível visualizar no quadro de № 4 abaixo:

Quadro №4. Pesquisa científicas sobre à questão étnico-racial no ensino de PFOL na UESC

\begin{tabular}{|c|c|c|c|c|}
\hline \multicolumn{5}{|c|}{$\begin{array}{l}\text { Quadro de pesquisas científicas sobre à questão étnico-racial na área de PFOL } \\
\text { desenvolvidas na Universidade Estadual de Santa Cruz - UESC }(2003-2020)\end{array}$} \\
\hline $\begin{array}{c}\text { Pesquisador } \\
\text { (a) }\end{array}$ & $\begin{array}{c}\text { Ano de } \\
\text { conclusão }\end{array}$ & Tema & Orientador (a) & $\begin{array}{c}\text { Instituição/ } \\
\text { Programa }\end{array}$ \\
\hline $\begin{array}{c}\text { Ana Vitória } \\
\text { Vieira Quinto }\end{array}$ & $\begin{array}{c}\text { Iniciação } \\
\text { Científica -2007 }\end{array}$ & $\begin{array}{l}\text { Ensino de Português } \\
\text { como Língua } \\
\text { Estrangeira }\end{array}$ & $\begin{array}{c}\text { Maria D'Ajuda } \\
\text { Alomba }\end{array}$ & UESC \\
\hline $\begin{array}{c}\text { Soade Pereira } \\
\text { Jorge }\end{array}$ & $\begin{array}{c}\text { Iniciação } \\
\text { Científica-2008 }\end{array}$ & $\begin{array}{c}\text { Aspectos Culturais na } \\
\text { interface dos romances } \\
\text { regionalistas: proposta } \\
\text { para o } \\
\text { ensino/aprendizagem } \\
\text { de português como } \\
\text { língua estrangeira e } \\
\text { segunda língua (L2/LE) }\end{array}$ & $\begin{array}{c}\text { Maria D'Ajuda } \\
\text { Alomba }\end{array}$ & UESC \\
\hline $\begin{array}{l}\text { Cássia dos } \\
\text { Santos } \\
\text { Teixeira. }\end{array}$ & $\begin{array}{l}\text { Dissertação de } \\
\text { Mestrado -2011 }\end{array}$ & $\begin{array}{l}\text { Livro didático de } \\
\text { PLE/LE- uma } \\
\text { perspectiva intercultural } \\
\text { na abordagem de } \\
\text { ensino. }\end{array}$ & $\begin{array}{l}\text { Maria D'Ajuda } \\
\text { Alomba }\end{array}$ & UESC/Pós \\
\hline $\begin{array}{c}\text { Gabriel } \\
\text { Nascimento } \\
\text { dos Santos }\end{array}$ & $\begin{array}{c}\text { Iniciação } \\
\text { Científica-2011 }\end{array}$ & $\begin{array}{c}\text { O Ensino de Português } \\
\text { como Língua } \\
\text { Estrangeira (PLE) e as } \\
\text { Tecnologias da } \\
\text { Informação e } \\
\text { Comunicação (TICs): a } \\
\text { busca de subsídios } \\
\text { tecnológicos e a sua } \\
\text { importância enquanto } \\
\text { difusores da cultura } \\
\text { brasileira.. }\end{array}$ & $\begin{array}{c}\text { Maria D'Ajuda } \\
\text { Alomba }\end{array}$ & UESC \\
\hline $\begin{array}{c}\text { Gabriel } \\
\text { Nascimento } \\
\text { dos Santos }\end{array}$ & $\begin{array}{c}\text { Iniciação } \\
\text { Científica-2011 }\end{array}$ & $\begin{array}{l}\text { Multiculturalismo na } \\
\text { rede: os blogs e as } \\
\text { redes sociais como } \\
\text { mecanismos de } \\
\text { comunicação } \\
\text { intercultural e a } \\
\text { interface Português } \\
\text { como Língua } \\
\text { Estrangeira. }\end{array}$ & $\begin{array}{l}\text { Maria D'Ajuda } \\
\text { Alomba }\end{array}$ & UESC \\
\hline $\begin{array}{l}\text { Maria Goretti } \\
\text { dos Santos } \\
\text { Silva }\end{array}$ & $\begin{array}{l}\text { Dissertação de } \\
\text { Mestrado -2011 }\end{array}$ & $\begin{array}{l}\text { As novas tecnologias } \\
\text { em interface com o } \\
\text { processo de formação } \\
\text { do professor de } \\
\text { PLE/PL2: uma }\end{array}$ & $\begin{array}{c}\text { Maria D'Ajuda } \\
\text { Alomba }\end{array}$ & UESC/Pós \\
\hline
\end{tabular}




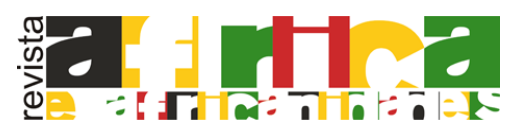

Revista África e Africanidades - Ano XIII - n. 34, maio. 2020 - ISSN 1983-2354 www.africaeafricanidades.com.br

\begin{tabular}{|c|c|c|c|c|}
\hline & & $\begin{array}{l}\text { abordagem identitária } \\
\text { multicultural brasileira. }\end{array}$ & & \\
\hline $\begin{array}{c}\text { Samara de } \\
\text { Oliveira Santos. }\end{array}$ & $\begin{array}{l}\text { Dissertação de } \\
\text { Mestrado -2011 }\end{array}$ & $\begin{array}{l}\text { Práticas metodológicas } \\
\text { para o Ensino de } \\
\text { Português como Língua } \\
\text { Estrangeira: proposta } \\
\text { pedagógica através da } \\
\text { cultura sul-baiana }\end{array}$ & $\begin{array}{l}\text { Maria D’Ajuda } \\
\text { Alomba }\end{array}$ & UESC/Pós \\
\hline $\begin{array}{c}\text { Rosana Souza } \\
\text { Silva }\end{array}$ & $\begin{array}{l}\text { Dissertação de } \\
\text { Mestrado-2012 }\end{array}$ & $\begin{array}{c}\text { Português como Língua } \\
\text { Estrangeira: o ensino } \\
\text { da variante brasileira } \\
\text { por meio do livro } \\
\text { didático. }\end{array}$ & $\begin{array}{l}\text { Maria D’Ajuda } \\
\text { Alomba }\end{array}$ & UESC/Pós \\
\hline $\begin{array}{l}\text { Élisson Victor } \\
\text { dos Santos } \\
\text { Ribeiro }\end{array}$ & $\begin{array}{c}\text { Iniciação } \\
\text { Científica-2014 }\end{array}$ & $\begin{array}{c}\text { Que língua-cultura } \\
\text { brasileira ensinar? Uma } \\
\text { pesquisa-ação sobre } \\
\text { PLE para } \\
\text { intercambistas } \\
\text { universitários na UESC. }\end{array}$ & Eduardo Pires & UESC \\
\hline $\begin{array}{l}\text { Élisson Victor } \\
\text { dos Santos } \\
\text { Ribeiro }\end{array}$ & $\begin{array}{l}\text { Trabalho de } \\
\text { Conclusão de } \\
\text { curso (TCC) - } \\
2015\end{array}$ & $\begin{array}{l}\text { O ensino-aprendizagem } \\
\text { de português como } \\
\text { segunda língua (PSL): } \\
\text { por uma abordagem } \\
\text { comunicativa } \\
\text { intercultural. }\end{array}$ & Eduardo Pires & UESC \\
\hline $\begin{array}{l}\text { Elane } \\
\text { Nascimento da } \\
\text { Silva. }\end{array}$ & $\begin{array}{c}\text { Iniciação } \\
\text { Científica -2015 }\end{array}$ & $\begin{array}{l}\text { O lugar do gênero } \\
\text { discursivo no } \\
\text { ensino/aprendizagem } \\
\text { de português como } \\
\text { segunda língua. }\end{array}$ & Eduardo Pires & UESC \\
\hline $\begin{array}{l}\text { Elane } \\
\text { Nascimento da } \\
\text { Silva }\end{array}$ & $\begin{array}{c}\text { Iniciação } \\
\text { Científica -2016 }\end{array}$ & $\begin{array}{c}\text { O componente } \\
\text { intercultural no ensino } \\
\text { de Português como } \\
\text { Língua Estrangeira: } \\
\text { bases teóricas, } \\
\text { natureza do ensino } \\
\text { intercultural e definição } \\
\text { dos conteúdos de } \\
\text { ensino. }\end{array}$ & Eduardo Pires & UESC \\
\hline $\begin{array}{c}\text { Amara } \\
\text { Sampaio de } \\
\text { Oliveira. }\end{array}$ & $\begin{array}{c}\text { Trabalho de } \\
\text { Conclusão de } \\
\text { Curso (TCC) - } \\
2016 \\
\end{array}$ & $\begin{array}{c}\text { Critérios para seleção } \\
\text { de textos literários no } \\
\text { ensino de português } \\
\text { para estrangeiros. }\end{array}$ & Eduardo Pires & UESC \\
\hline $\begin{array}{c}\text { Rebeca Santos } \\
\text { Rangel. }\end{array}$ & $\begin{array}{c}\text { Iniciação } \\
\text { Científica-2018 }\end{array}$ & $\begin{array}{l}\text { A produção escrita no } \\
\text { discurso do livro } \\
\text { didático de Português } \\
\text { como Língua } \\
\text { Estrangeira. }\end{array}$ & Eduardo Pires & UESC \\
\hline $\begin{array}{l}\text { Sara Bispo } \\
\text { Menezes }\end{array}$ & $\begin{array}{c}\text { Iniciação } \\
\text { Científica -2018 }\end{array}$ & $\begin{array}{l}\text { Práticas de escuta e } \\
\text { fala no ensino de } \\
\text { português para falantes } \\
\text { de outras línguas }\end{array}$ & Eduardo Pires & UESC \\
\hline $\begin{array}{c}\text { Bruno Bomfim } \\
\text { Vieira }\end{array}$ & $\begin{array}{c}\text { Iniciação } \\
\text { Cientifica-2018 }\end{array}$ & $\begin{array}{l}\text { A produção escrita no } \\
\text { discurso do livro } \\
\text { didático de português } \\
\text { para falantes de outras } \\
\text { línguas }\end{array}$ & Eduardo Pires & UESC \\
\hline
\end{tabular}




\begin{tabular}{|c|c|c|c|c|}
\hline $\begin{array}{l}\text { Natasha } \\
\text { Susmaga } \\
\text { Vargas }\end{array}$ & $\begin{array}{l}\text { Trabalho de } \\
\text { Conclusão de } \\
\text { Curso (TCC) - } \\
2016\end{array}$ & $\begin{array}{c}\text { Leitura e } \\
\text { interculturalidade no } \\
\text { ensino de Português } \\
\text { como Língua } \\
\text { Estrangeira: análise do } \\
\text { livro didático Brasil } \\
\text { Intercultural }\end{array}$ & Eduardo Pires & UESC \\
\hline $\begin{array}{c}\text { Elane } \\
\text { Nascimento da } \\
\text { Silva }\end{array}$ & $\begin{array}{l}\text { Trabalho de } \\
\text { Conclusão de } \\
\text { Curso (TCC)- } \\
2017\end{array}$ & $\begin{array}{l}\text { O funcionamento do } \\
\text { discurso do CELPE- } \\
\text { Bras: Lugares } \\
\text { (im)possíveis para o } \\
\text { sujeito examinando }\end{array}$ & Eduardo Pires & UESC \\
\hline $\begin{array}{c}\text { Cecília Souza } \\
\text { Santos } \\
\text { Sobrinha }\end{array}$ & $\begin{array}{l}\text { Dissertação de } \\
\text { Mestrado-2018 }\end{array}$ & $\begin{array}{l}\text { Ensino de Português } \\
\text { como Língua } \\
\text { Estrangeira: o discurso } \\
\text { de interculturalidade na } \\
\text { proposta de ensino de } \\
\text { produção escrita do } \\
\text { livro didático Brasil } \\
\text { Intercultural }\end{array}$ & Eduardo Pires & UESC/Pós \\
\hline $\begin{array}{c}\text { Patrícia } \\
\text { Alejandra } \\
\text { Faúndez Ríos }\end{array}$ & $\begin{array}{l}\text { Dissertação de } \\
\text { Mestrado -2019 }\end{array}$ & $\begin{array}{l}\text { Concepções de tarefa } \\
\text { no livro didático de } \\
\text { Português como Língua } \\
\text { Estrangeira para } \\
\text { profissionais. }\end{array}$ & Eduardo Pires & UESC/Pós \\
\hline
\end{tabular}

Fonte: Dados elaborados pelo autor a partir de informações da Plataforma Lattes e Programa de Pós-Graduação em Letras: Linguagens e Representações da UESC.

Conforme é percebido nos quadros 3 e 4 , as pesquisas desenvolvidas no campo de PFOL no contexto da Universidade Federal da Bahia e da Universidade Estadual de Santa Cruz são posteriores à promulgação da referida Lei 10.639/2003. Todavia, as relações étnico-raciais ainda aparecem de forma ínfimas nas pesquisas, o que configura-se uma expressiva discrepância, considerando a realidade sociocultural baiana e a embriose entre a indissociabilidade do ensino prevista no artigo 207 da Constituição Federal de 1988, o qual atesta que "as universidades gozam de autonomia didáticocientífica, administrativa e de gestão financeira e patrimonial, e obedecerão ao princípio de indissociabilidade entre ensino, pesquisa e extensão". (BRASIL, 1988). Dessa maneira, considero aqui a importância das relações étnico-raciais no ensino e nas pesquisas, como temática central, não como tema secundário.

Diante do exposto, é nítido perceber que as pesquisas desenvolvidas no interior das universidades, de certa maneira, não contemplam a diversidade da cultura africana e afro-brasileira tão presente na sociedade baiana. Portanto, esse formato de elaboração de pesquisa não dialoga com seu entorno e não responde às demandas do ensino existentes no seu próprio lócus, além de desconsiderar o importante papel dos negros na constituição da cultura brasileira e da língua portuguesa.

\section{QUESTÕES HISTÓRICAS RELEVANTES}

Convém lembrar que a Bahia foi uma região pela qual recebeu um intenso fluxo de pessoas negras escravizadas e transportadas forçadamente de diversas 
regiões do continente africano para trabalharem de forma totalmente precária nas fazendas e nos engenhos baianos. Nesse prisma, segundo o historiador baiano João Reis (2003), o tráfico de escravizados foi um dos negócios mais lucrativos no comércio baiano. Concentrava-se na região baiana, grande parte, talvez a maior, do tráfico de negros africanos que rendeu aos que os exploravam uma enorme e desonesta riqueza, à base da exploração da mão de obra dos povos negros capturados da África e levados forçadamente para a Bahia, entre os séculos XVI e XIX, durante o período colonial.

Na afirmativa do pensador baiano João Reis (2003), para além da trágica história de escravização, exploração da mão de obra e apropriação dos corpos negros para geração de riquezas dos exploradores portugueses, a Bahia foi também palco de um ciclo de resistências, revoltas e conspirações durante a primeira metade do século XIX. Dentre elas, a mais conhecida foi a Revolta dos Malês, ocorrida em 1835, na qual, os malês, negros de origem islâmica, organizaram um levante justamente por não concordarem com a precária situação na qual viviam.

Compreende-se, portanto, que os povos negros africanos escravizados não concordaram com as diversas formas de opressões nas quais estavam sujeitos, mas resistiram e resistem sempre contra todos os modos e tentativas de violência as quais foram submetidos. Assim, é necessário também resistir ao epistemicídio, que opera de forma sofisticada com o intuito de apagar os sujeitos negros dos processos de construção de epistemologias. Como bem expõem Santos, Pinto e Chirinéa (2018):

\begin{abstract}
O extermínio de saberes africanos e afro-brasileiros é garantido por meio de arranjos que cerceiam a produção e divulgação de conhecimentos negros por meio de diferentes artimanhas: pela contestação e invalidação de epistemologias e formas de conhecimentos africanos; por meio da escassez de negras e negros nos postos de saber institucionalizados (branqueamento da educação); através da ausência/escassez de conteúdos relacionados às questões negras/africanas nos currículos oficiais e trabalhados de formas coerentes; e, por fim e, como consequência das artimanhas anteriores, pelo não desenvolvimento de tecnologias, soluções e conhecimentos voltados para as demandas da população negra.
\end{abstract}

Corroborando plenamente com a ideia exposta pelas pensadoras, faz-se necessário pontuar que dada a grande massa de sujeitos negros escravizados trazidos para o Brasil no período colonial, ainda hoje os negros constitui-se como o maior contingente populacional do estado da Bahia. Porém, a maioria dos negros ainda estão excluídos dos espaços de tomada de decisões e poder nas instituições acadêmicas, sejam elas públicas ou privadas.

Os negros continuam sendo, de certo modo, os mais excluídos de espaços de poder, como as universidades, na qualidade de docentes dos programas de pós-graduação, que são espaços privilegiados de produção de saberes, e também historicamente ocupados, na sua maioria, por homens brancos que, em certa medida, gozam dos privilégios gerados pelo processo sistêmico de racismo contra os negros, que foram e ainda são os mais desfavorecidos pelo mesmo processo histórico de racismo estrutural brasileiro. 
É relevante sublinhar que os povos negros capturados da África para a região da Bahia, trouxeram consigo uma riquíssima e vasta diversidade sociocultural e linguística, que alterou de forma significativa a cultura brasileira, a língua portuguesa de base europeia, as diversas línguas-culturas indígenas e, posteriormente, as línguas e culturas africanas que eram faladas em diferentes contextos na Bahia, no Período Colonial.

A professora baiana Rosa Virgínia de Mattos e Silva (2004), explicita em uma de suas obras denominada Ensaios para Uma Sócio-História do Português Brasileiro, "o papel preponderante da população de origem africana como difusora do que veio a ser chamado de português popular brasileiro pela sociolinguística contemporânea", a despeito do por ela designado português culto brasileiro. Nesse prisma, o ensino e a aprendizagem de língua portuguesa, assim como as pesquisas científicas, ainda que numa perspectiva de língua estrangeira, na contemporaneidade, não se deve invisibilizar a importante presença africana e dos afrodescendentes nesse processo de constituição da língua portuguesa brasileira.

Nesse mesmo caminho, é importante sublinhar que, ainda de acordo com o pensamento da linguista Mattos e Silva (2014, p. 99), até meados do século $\mathrm{XVIII}$ teria predominado um multilinguismo generalizado no Brasil e, nesse mesmo período, ocorre a política linguístico-cultural pombalina, a qual torna-se pelo decreto do lusitano Marques de Pombal, a língua portuguesa oficial no Brasil, proibido o uso das línguas indígenas e expulsando os Jesuítas que, em suas catequeses, davam suporte à língua geral, em prol do português.

A grande massa dos povos negros africanos, os quais foram trazidos para o Brasil, desde a quarta década do século XVI até o XIX, mesmo com o término do tráfico oficial em 1830, com as suas 200/300 línguas e culturas, teve de aprender de forma imposta a língua dos senhores, por meio de um contexto precário de exposição à língua veicular, a portuguesa.

Dessa forma, ainda com base na assertiva de Mattos e Silva (2014, p.100), os povos negros africanos contribuíram significativamente com as suas línguas e culturas para a constituição e difusão do que conhecemos hoje pela sociolinguística como português popular brasileiro. Portanto, a influência dos povos africanos, afro-brasileiros e indígenas foi fundamental para alterar/fraturar e diversificar a língua portuguesa de variante europeia no período colonial.

Nessa direção, no que se refere à sócio história da constituição do português brasileiro, a relevante contribuição dos povos negros africanos e afrobrasileiros como um dos principais fatores de difusão do que conhecemos como português popular brasileiro, é substancial ratificar que, de acordo com os escritos de Almeida Filho (2011), na Bahia, no período colonial já havia iniciativas práticas de ensino de Português para Falantes de Outros Línguas (PFOL), porém sem uma consciência como prática de ensino profissional, conforme é explicitado nos seus relatos a seguir:

[...] a prática do ensino de Português como Língua Estrangeira (PLE) tem história relativamente antiga para um país pós-colonial, mas a consciência de área profissional e científica não passa de aproximadamente mais de duas décadas. $O$ ensino de línguas existe no Brasil desde a fundação das primeiras escolas jesuíticas, na 


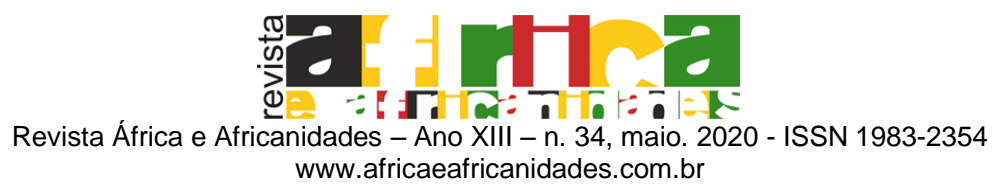

fundação colonial que durou por volta de duzentos anos, entre 1500, ano da chegada dos primeiros exploradores portugueses à costa da Bahia e de uma forma imposta ensinavam sua língua portuguesa aos povos indígenas que já residiam nas terras, e em 1808, ano da chegada da Família Real portuguesa a Salvador, primeiramente, e posteriormente ao Rio de Janeiro. (ALMEIDA FILHO, 2011, p.160162).

Com base no excerto sobre as iniciativas práticas e não conscientes de Ensino e a aprendizagem de Português para Falantes de outras Línguas na Bahia, (doravante PFOL), faz-se necessário explicitar que a Bahia foi protagonista, ou seja, o primeiro lugar no qual a língua portuguesa, ainda na sua variante europeia, foi ensinada e difundida para falantes de outras línguas e culturas, a saber, os povos africanos, os quais foram trazidos na condição de escravizados dentro dos chamados navios negreiros, bem como aos afrobrasileiros e aos povos nativos, os povos principais originários da terra, que já habitavam na região da Bahia antes mesmo da chegada do invasor colonizador português.

Diante do exposto, no que tange à sócio história e às importantes contribuições linguístico-culturais dos povos negros africanos e, posteriormente, dos afrodescendentes para a constituição do português brasileiro, é fundamental reconhecer que o ensino e a aprendizagem de português para estrangeiros na contemporaneidade, no contexto das universidades públicas baianas, não pode desprezar a sócio história, a participação ativa e as importantes colaborações dos povos negros africanos e afro-brasileiros para a língua portuguesa e cultura brasileira.

Ainda nesta direção, na assertiva da professora Maria Ortiz Alvarez (2011), o processo de ensino e aprendizagem de uma dada língua materna ou estrangeira não pode desprezar a cultura do seu entorno, pois desprezar o seu entorno é ensinar uma língua sem um real sentido e alheia ao seu potencial valor cultural. Dessa maneira, o ensino de português para estrangeiros no contexto da Bahia precisa levar em consideração o processo sócio-histórico e os seus principais atores sociais, os falantes da língua portuguesa, os quais influenciaram diretamente na constituição dessa língua, a saber, os povos negros africanos transportados de África, os afro-brasileiros, os indígenas, os exploradores portugueses etc.

Na concepção da professora Maria Alomba Ribeiro (2013), o ensino de uma língua estrangeira e, principalmente do português para estrangeiros, no espaço da sala de aula, configura-se como um grande desafio para o professor, pois ensinar uma língua não se restringe a conhecer a nomenclatura gramatical, mas, sobretudo, apresentar ao aprendiz aspectos da língua e cultura alvo que Ihe farão mais sentido em seus diversos usos sociais e lhe permitirão agir e interagir ativamente na cultura do outro. Portanto, o ensino de uma língua deve ser realizado de forma crítica e objetivando contribuir para formação de cidadãos mais conscientes politicamente e antirracistas.

Nessa perspectiva, o professor mediador do ensino de português para estrangeiros precisa se mobilizar para buscar conhecer de forma mais ampla as culturas nas quais essa língua está inserida. Isso deve ser feito para que não se 


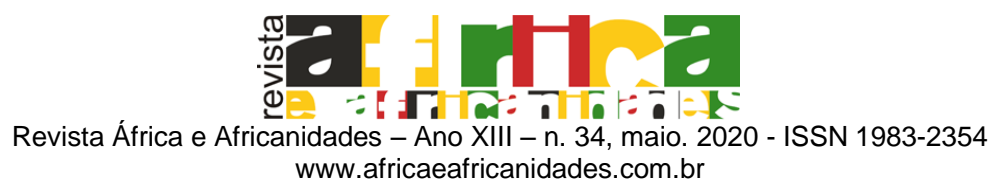

cometam preconceitos, como o racismo antinegros, para que não se reproduzam estereótipos culturalmente recorrentes na sociedade, ou restrinjam o processo de ensino e a aprendizagem a aspectos isolados e internos à língua e cultura, isso ocorre devido à ausência ou limitação de uma compreensão mais holística sobre a língua e a cultura alvo que se pretende ensinar, viver e interferir.

Ainda na visão de Maria Alomba Ribeiro (2013), "ensinar uma língua estrangeira é oferecer aos alunos vários caminhos, entendendo que um desses caminhos é emergir na cultura da língua-alvo". Nesse sentido, é extremamente pertinente que o professor mediatário não ensine apontando apenas um único horizonte cultural, mas é importante apresentar uma diversidade de horizontes pelos quais os aprendizes tenham acesso a diversas perspectivas de representação da língua que se pretende adquirir e não apenas uma perspectiva unilateral da língua ou brancocêntrica. É importante que o professor medeie suas aulas tendo muito cuidado para não propagar/reproduzir ou expor os seus preconceitos com relação à língua e cultura alvo e limitar, assim, a aprendizagem dos estudantes.

Com base nas discussões sobre o lugar das culturas africanas e afrobrasileiras no ensino de PFOL no contexto das universidades baianas, faz-se necessário pontuar que, de acordo com o pensamento de Maria Alomba Ribeiro (2013), cultura é tudo aquilo que é produzido pelo ser humano, ou seja, todas as formas de saberes, manifestações, costumes, línguas e os diferentes modos de ser e atuar na sociedade. Dessa forma, as culturas africanas também têm de ser visibilizadas de forma mais efetiva, e não negada ou apresentada de forma estereotipada ou folclorizada no ensino de língua portuguesa para estrangeiros na contemporaneidade, sobretudo no contexto das Instituições Públicas de Ensino Superior em solo baiano.

Cabe ressaltar que o Brasil foi estruturado no racismo e as formas veladas, desveladas, conscientes ou inconscientes perpassam por todas as estruturas institucionais brasileiras, a saber, o sistema de justiça, a escola, a universidade, o hospital, a família, a igreja, os meios de comunicação etc. No que tange à educação escolar, que é o foco dessa pesquisa, as formas de racismo operam de diversas maneiras, uma delas é o próprio discurso de negação do racismo na sociedade brasileira, a escassez de pesquisas científicas, a sub-representação de negros em posição de poder/prestígio social nos livros didáticos, a ausência de heróis negros nos desenhos animados e nos livros infantis, entre outros exemplos como bem demostrou a pesquisa da escritora negra Ana Célia no seu Livro: A discriminação do Negro no Livro didático (2004), publicado pela Editora EDUFBA.

Por outro lado, ainda é muito recorrente visualizarmos nos livros e meios de comunicação a representação social das mulheres negras como cozinheiras, babás, fazendo, quase sempre, uma analogia/alusão às mulheres negras escravizadas no período colonial, à hipersexualização dos corpos de mulheres e de homens negros ou apresentando-os meramente como $\mathrm{m}$ objeto de prazer sexual casual fácil.

Além disso, há também as representações de formas animalizadas e folclorizadas dos corpos negros e a relação do ser negro com animais, como o 


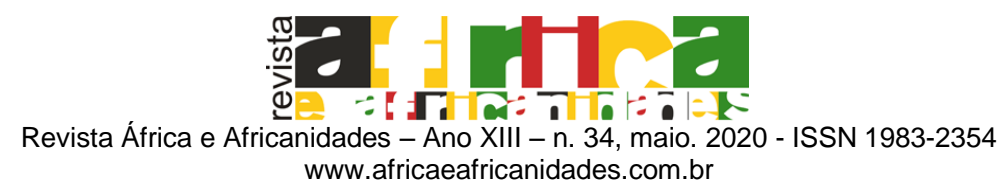

macaco, que se revela como uma tentativa de afirmar que o ser negro não possui, de certa forma, humanidade, que é, portanto, uma das táticas do racismo contra os negros. Essas e outras formas de sub-representação dos corpos negros em posição de eminência social nos livros didático são evidências nítidas de que a nossa sociedade é estruturalmente racista, com raras exceções, claro!

Ainda persiste no imaginário coletivo de grande parcela da população brasileira a existência de uma democracia racial, a qual foi muito propagada por Gilberto Freire em uma de suas obras Casa Grande e Senzala, além de outros pensadores no Brasil. Mas esse pensamento já está totalmente deslegitimado pelo movimento negro, por aqueles que possuem consciência racial e que compreendem minimamente a história do cruel processo de escravização dos negros e percebem às suas nítidas consequências na vida da maioria dos negros e dos seus descendentes na contemporaneidade.

Um dos exemplos desse trágico processo de escravização é o encarceramento em massa da população negra, assunto muito bem elucidado por escritoras negras, como a baiana Carla Akotirene, Denise Carrascosa, a Norte Americana Ângela Davis, além da escritora Juliana Borges. Ademais da sub-representação dos negros no Supremo Tribunal Federal - STF, nos cargos de alto escalão governamentais, nas reitorias das universidades brasileiras, no corpo docente do Magistério Superior, nas câmaras municipais e nos papéis de maior prestígio social, os quais envolve status social e, sobretudo, grandes retornos pecuniários.

Diante do quadro exposto acima, é substancial discorrer que a representação/expressão da língua/linguagem ainda é muito utilizada para realizar e reforçar o racismo no contexto da educação e em outros contextos. Isso é sintoma ou reflexo de parte de uma sociedade que ainda não conseguiu descolonizar plenamente o seu pensamento sobre questões relacionadas aos negros, talvez porque a escola, a construção de epistemologias, os currículos e os livros didáticos ainda não conseguiram se desatar completamente da ideologia culturalmente racista.

Obviamente que a expressão dos discursos históricos e culturalmente racistas são materializados também nos textos, a saber, no verbal, não-verbal, verbo-visual que, infelizmente, são ainda muito utilizados de forma consciente ou inconscientes, até mesmo por muitos professores, em muitos mateirias didáticos, como recursos pedagógicos em contextos escolares. Isso ainda é recorrente, talvez em consequência da ausência de uma boa formação escolar antirracista, da falta de uma consciência racial e política, ou mesmo porque julgam que tais questões sejam pouco relevantes.

Nessa esteira, ressalta-se o posicionamento da pesquisadora negra Nilma Lino Gomes (2018), a qual afirma que:

[...] ao politizar a raça, o movimento negro desvela a sua construção no contexto das relações de poder, rompendo com visões distorcidas, negativas e naturalizadas sobre os negros, sua história, cultura, práticas e conhecimentos; retira a população negra do lugar da suposta inferioridade racial pregada pelo racismo e interpreta afirmativamente a raça como construção social; coloca e xeque o mito da igualdade racial. (LINO GOMES, 2018, p. 22). 


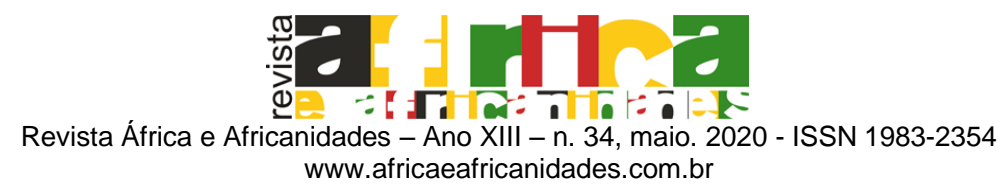

Assim, ainda na perspectiva de (LINO GOMES 2018, p. 22) o fator raça e identidade étnico-racial na compreensão do movimento negro brasileiro são utilizados não apenas como instrumento de mobilização, mas também de mediação das reivindicações políticas (DOMINGUES, 2017). O mesmo fator raça que tem sido historicamente apropriado por grupos raciais brancos para segregação dos negros tem sido também motor determinante de articulação coletiva dos negros em torno de um projeto comum de ação e luta antirracista em todas as esferas da sociedade brasileira, e principalmente, no âmbito da educação escolar.

Na lógica do pensador negro Silvio Almeida (2018, p. 24), "a noção de raça ainda é um fator político importante, utilizado para naturalizar desigualdades, justificar a segregação e o genocídio de grupos sociologicamente considerados minoritários". Nesse aspecto, é importante sublinhar que todas as formas de racismo antinegros operam a partir do registro característica biológica, em que a identidade racial será atribuída por algum traço físico, como cor de pele; e como característica étnico-cultural, ou seja, em que a identidade será associada à origem geográfica, à religião, estrato social, à língua, ou a outros costumes e crenças. Ainda nessa direção, para Silvio Almeida (2018), à configuração de processos discriminatórios a partir do registro étnico-cultural, Frantz Fanon denomina Racismo Cultural.

A questão étnico-racial deveria ser o elemento mais presente das pesquisas científicas produzidas no campo específico de ensino de português para estrangeiros, no âmbito das instituições públicas baiana. Por ser um componente que existe na vida e nas relações sociais deveria ser também inserida como temática central das investigações engendradas em instituições que estão situadas em um território o qual é constituído historicamente, na sua maioria, por sujeitos negros.

Está claro que o ensino de língua portuguesa e cultura brasileira para estrangeiros assim como as produções de pesquisas têm sido incipientes no quesito questão étnico-racial. Isso se dá também em decorrência da ínfima atenção que os currículos conferem às relações étnico-racial nos cursos de Letras Vernáculas.

A insuficiência ou escassez de pesquisas sobre a questão étnico-racial no contexto das universidades baianas é um ponto bastante problemático, pois a ausência também contribui para a inação dos sujeitos envolvidos nesse processo de ensino e aprendizagem perante a luta antirracista na educação e na sociedade. E o que se torna o maior agravante é a surpreendente revelação do distanciamento do ensino de língua portuguesa para estrangeiros da real diversidade étnico-cultural baiana.

Cabe expor que o ensino de português a falantes estrangeiros por uma perspectiva que se pretende intercultural não deve desprezar uma questão de tamanha relevância sociocultural, como é a questão étnico-racial, já que ensinar uma língua não se limita a falar apenas sobre aspectos intralinguísticos, mas é, sobretudo, apresentar quem são os sujeitos históricos que a usam e interagem com e por meio dessa língua. 


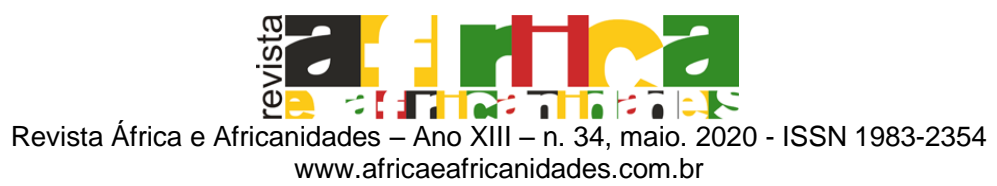

\section{CONSIDERAÇÕES FINAIS}

Remontando ao título desse artigo, é pertinente interpelar a seguinte proposição: qual é o lugar da cultura afro-brasileira e africana no ensino de português para falantes de outras línguas no contexto das universidades públicas da Bahia? De certa forma, as relações étnico-raciais ainda têm sido preteridas como temática central na grande maioria das pesquisas realizadas no campo de PFOL no cenário das universidades aqui investigadas.

A diversidade étnico-cultural do estado da Bahia se constituiu, de certo modo, mediante a resistência de mulheres e homens negros, que a custo de muita luta e sangue derramado, conseguiram manter viva e valorizar a língua e as culturas dos aguerridos antepassados negros. Por conseguinte, o minúsculo tratamento que é dado à questão cultural dos povos negros nas pesquisas e na matriz curricular, como apontam os dados, é gritante e precisa ser questionado, pois a universidade deve valorizar nas suas pesquisas a diversidade cultural afro-baiana.

A grande preocupação decorrente do vácuo ocasionado pelo pouco quantitativo de pesquisas sobre as questões raciais no ensino de PFOL representa, de certa forma, a resistência da academia para incluir nos seus currículos, pesquisas cientificas e cursos de extensão tais temáticas. Para além disso, os dados comprovam que não se dá a devida atenção à Lei 10.639 de 2003 e suas diretrizes, ou há, em certa medida, um desconhecimento ou pouco interesse por parte dos acadêmicos-pesquisadores que atuam nesse campo específico do saber.

Essas ausências das questões étnico-raciais corroboram, de certo modo, para a formação deficitária de professores que atuarão sem o mínimo suporte teórico-metodológico e sem saberem efetivamente ensinar a importância e o protagonismo dos sujeitos negros no processo de constituição da língua portuguesa e cultura brasileira. Dessa forma, essas lacunas na formação contribuem para com uma formação de professores letárgicos frente ás questões sobre o racismo e à discriminação racial no contexto da educação escolar, além de não contribuir para a erradicação do racismo no ambiente escolar e na sociedade como um todo.

Diante do exposto, é fundamental que a sociedade civil, os estudantes, os movimentos sociais, e os sujeitos com uma boa formação antirracista cobrem das instituições de ensino superior a construção de mais mecanismos e estratégias que pautem, de forma significativa, a questão étnico-racial na matriz curricular dos cursos de Letras, nos projetos de extensão, bem como nos projetos dos grupos de pesquisas na área de ensino e aprendizagem de português para falantes de outras línguas.

Portanto, seguindo a orientação da pensadora Ângela Davis, numa sociedade racista, como é a brasileira, não basta ser não racista, e sim antirracista. Sendo assim, cabe a universidade, que é o lugar de formação de professores e um dos lugares de produção de saber, repensar qual é o seu papel na luta antirracista e agir no sentido de combater veementemente as formas de racismo, caso contrário estará corroborando diretamente para a manutenção e propagação dessa prática na sociedade. 


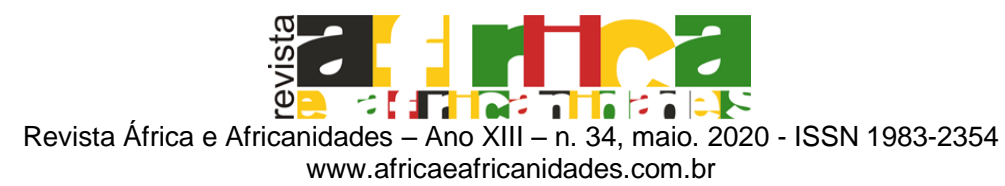

\section{REFERÊNCIAS}

ALOMBA RIBEIRO, Maria D'Ajuda. (Re) significações no ensino de Português Língua Estrangeira: Teoria e Aplicação. In: Kléber Aparecido da Silva e Danúsia Torres dos Santos. (Org.). Português como Língua (inter) nacional: faces e interfaces I. xed. Campinas-SP: Pontes Editores, 2013, v. 1, p. 05-10.

ALMEIDA FILHO, J. C. P. Fundamentos de abordagem e formação no ensino de PLE e de outras línguas. Campinas: Pontes, 2011.

ALMEIDA, Silvio Luiz de. O que é racismo estrutural? Belo Horizonte (MG): Letramento, 2018.

ALVAREZ, M. L. O. Políticas de difusão e formação crítica em PLE: por uma formação por competências. In: Edleise Mendes. (Org.). Diálogos interculturais: ensino e formação em Português língua estrangeira. 1ed.Campinas: Pontes editores, 2011, v. 1, p. 173-206.

BRASIL. Constituição da República Federativa do Brasil: promulgada em 5 de outubro de 1988. Brasília: Senado Federal, 1988.

BRASIL. Lei 10.639/2003, de 9 de janeiro de 2003. Altera a Lei no 9. 394, de 20 de dezembro de 1996. Diário Oficial da União, Poder Executivo, Brasília.

BRASIL. Ministério da Educação. "Plano Nacional de Implementação das Diretrizes Curriculares Nacionais da Educação das Relações Étnico-Raciais e para o Ensino de História e Cultura Afro-brasileira e Africana". Novembro de 2009.

DOMINGUES, Petrônio. Movimento negro brasileiro: alguns apontamentos históricos. Tempo [online]. 2007, vol.12, n.23, pp.100-122.

GOMES, N.L. O movimento negro educador. Petrópolis: Vozes, 2018.

IBGE. Disponível em: www.ibge.gov.br. Acesso em 22 de janeiro. 2019.

Mattos e Silva R.V. Ensaios para uma sócio-história do português brasileiro. São Paulo: Parábola; 2004.

MORAES, R. B.; SOUZA, I. L. O Português para Falantes de Outras Línguas na Bahia: Avanços e Desafios. In: XX SEMOC/UCSAL - Semana de Mobilização Científica:

Saúde, Tecnologias e Desenvolvimento Humano, 2017, Salvador. Anais da XX SEMOC - Semana de Mobilização Científica: Saúde, Tecnologias e Desenvolvimento Humano. Salvador: Universidade Católica de Salvador, 2017. v. Anais. p.1029-1037.

REIS, João José. Rebelião Escrava no Brasil: A História do Levante dos Malês em 1835. São Paulo: Companhia das Letras, 2003.

SILVA, Ana Célia da. A Discriminação do Negro no Livro Didático. 2 ed. Salvador: EDUFBA, 2004.

SILVA, K. A da ; SANTOS, D. T. (Orgs.). Português como Língua (Inter) Nacional: Faces e Interfaces. Campinas, SP. Pontes Editores, 2017. 